\title{
The Vignette for V13N4 issue
}

\section{Polypyrimidine-tract-binding protein (PTB), a new cellular factor for hepatitis $C$ virus $R$ NA replication}

Hepatitis $\mathrm{C}$ virus (HCV) is an important cause of chronic hepatitis, liver cirrhosis and hepatocellular carcinoma. The understanding of mechanism of viral replication is crucial for the development of new therapy. Previously, HCV RNA replication was shown to require viral nonstructural proteins. Increasingly it is being recognized that cellular factors are also involved in viral replication. In the current study [1], Aizaki et al. analyzed a cell line containing an HCV subgenomic replicon and showed that PTB, which binds to the $5^{\prime}$ and $3^{\prime}$-untranslated regions of HCV RNA, is involved in HCV RNA replication. Since PTB was shown to be required for HCV translation as well [2], PTB is a new class of "dual-function" cellular protein involved in HCV replication. This could be a potential target for antiviral therapy.

A DNA vaccine encoding a codon-optimized Human Papillomavirus Type 16 E6 gene enhances CTL response and anti-tumor activity

HPV-16 E6 is consistently expressed in HPVassociated cancer cells and is responsible for their malignant transformation. Thus, E6 represents an ideal target antigen for developing vaccines against HPV-associated neoplasms [3]. Several HPV vaccines targeting E6 have been developed [4]. In the current study, Lin et al. developed a codonoptimized HPV-16 E6 DNA vaccine [5]. They demonstrated that codon optimization of E6 can lead to a highly efficient translation of E6, resulting in increased E6-specific $\mathrm{CD}^{+} \mathrm{T}$ cell immune responses and better anti-tumor effects in vaccinated mice. Thus, DNA vaccines encoding a codon-optimized HPV-16 E6 may be a promising strategy for improving the potency of therapeutic HPV vaccines.
A comparison of major histocompatibility complex SNPs in Han Chinese residing in Taiwan and Caucasians

Human major histocompatibility complex (MHC) region is highly polymorphic and has been intensively analyzed to study genetic susceptibility of complex diseases [6]. Since the MHC region has also been shown to vary between populations [7], detailed examination of ethnic heterogeneity becomes essential before initiating any large-scale disease gene mapping study [8]. Yang et al. [9] compared genotypic distributions, linkage disequilibria and haplotype blocks between Caucasian and Taiwan's Han Chinese populations and revealed that genotypic information of Taiwan's Han Chinese is quite different from Caucasians but are relatively homogeneous among the three major ethnic subgroups, Minnan, Hakka and Mainlanders. This information has established a foundation for future disease gene mapping studies.

\section{Effects of siRNAs in combination with Gleevec on K-562 cell proliferation and Bcr-Abl expression}

Both synthetic siRNA, consisting of 21-nucleotide RNA duplexes specific for the Ber- $A b l$ fusion site, and recombinant(r) - generated (Bcr)-Abl siRNA were generated. The Bcr-Abl transcription in K-562 cells [10] was inhibited by either siRNA transcription, and $\mathrm{IC}_{50}$ of Gleevec in the K-562 cells was lowered over 3 -fold from 0.2 to $0.06 \mu \mathrm{M}$ in cells transfected by the siRNAs. It suggests that the treatment of CML patients with Gleevec and the siRNA could enhance the efficiency of therapy [11].

\section{Oxygen-dependent neuroglobin mRNA regulation in the anoxia-tolerant turtle brain}

Neuroglobin is a recently discovered heme protein that is localized to nervous tissue and has been reported in mammals, fishes, and birds [10]. The 
potential functions of neuroglobin include those of oxygen carrier, oxygen sensor, scavenger of reactive oxygen species and neuroprotectant molecule. As the brain of the freshwater turtle is extremely anoxia-tolerant, it provides an interesting alternative model to study the regulation and potential roles of neuroglobin [13]. In this issue, Milton et al. [14] report oxygen-dependent regulation of neuroglobin mRNA expression in the anoxiatolerant turtle brain. Messenger RNA levels for neuroglobin increased 3.5 fold over $4 \mathrm{~h}$ hypoxia whereas only a 2 fold increase was seen by $4 \mathrm{~h}$ anoxia. On reoxygenation after anoxia, a 4.7 fold increase relative to normoxia was observed. The greater induction of $\mathrm{Ngb}$ by hypoxia compared to anoxia, together with a high-level induction upon re-oxygenation, indicates a hypoxia-specific role for neuroglobin, perhaps as an ROS scavenger. Our observations suggest a key protective role for neuroglobin in mediating brain anoxic survival.

\section{Motor functions but not learning and memory are impaired upon repeated exposure to sub-lethal doses of methyl parathion}

Repeated exposure of mammals to organophosphate pesticides (OP) lead to tolerance to central nervous toxicities including salivation, lacrimation, excessive urination, localized fasciculation and tremor [15, 16], effects evoked by cholinergic over-stimulation as the results of acethylcholinesterase (AChE) inhibition [17]. In addition, psychiatric sequelae of depression, loss of concentration, difficulty in thinking, and especially memory impairment are also noted in patients chronically exposed to OP [18]. Whether these CNS toxic effects to repeated exposure to OP are attributed to AChE inhibition is here-to-fore unknown. Sun et al. [19] reported that in rats, repeated treatment of methyl parathion (MP), a restricted OP compound used as a pesticide on agriculture crops, suppressed the locomotor activity but spared the associative learning and memory. The motor dysfunctions in the MP-treated rats are mediated by reciprocal balance between cholinergic and dopaminergic systems at striatum following cholinergic over-stimulation. The authors provide evidence to indicate that the CNS toxicities induced by repeated exposure to MP cannot be attributed entirely to the inhibition of brain AChE.

\section{Organic anion transporting polypeptide-C and arsenic uptake}

Organic anion transporting polypeptides (OATPs) are membrane solute carriers (SLCs) that are main players in the sodium-independent transport system. OATPs are known to transport a broad spectrum of substrates [20]. OATP-C (or, OATP1B1) is also called OATP-2 or liver-specific transporter 1 (LST-1). It is expressed predominantly at the basolateral membrane of hepatocytes [21]. Arsenic is known to cause cancer and vascular disease as well as skin lesions in humans [22]. In order to examine whether organic anion transporting polypeptide-C (OATP-C) also plays a role in arsenic transport, OATP-C cDNA was transfected into cells of a human embryonic kidney cell line (HEK-293). Result demonstrated that transfection of OATP-C increased uptake and cytotoxicity of arsenate and arsenite, but not of MMAV or DMAV. Rifampin and taurocholic acid (a substrate of OATP-C) reversed the increased toxicity of arsenate and arsenite seen in OATP-C-transfected cells. This study suggests that OATP-C can transport inorganic arsenic in a (GSH)-dependent manner. However, this may not be the major pathway for arsenic transport [23].

\section{Gypenoside XLIX isolated from Gynostemma pentaphyllum inhibits nuclear factor- $\mathrm{K} B$ activation via a PPAR- $\alpha$-dependent pathway}

Identifying potential medicinal active component from natural products and elucidating its mode of action have become an important research area. Gynostemma pentaphyllum (Cucurbitaceae), known as Jiagulan in Chinese herbal medicine, has been widely used to treat inflammation, tumor or ulcer etc. [24, 25]. Recently, a dammarane-type gynosaponin, has been isolated from Gynostemma pentaphyllum and shown to activate LXR- $\alpha$ receptor in HEK293 cells [26]. Huang et al. [27] reported that Gyp-XLIX, a naturally occurring gynosaponin, inhibits $\mathrm{NF}-\kappa \mathrm{B}$ activation via a PPAR- $\alpha$-dependent pathway in murine macrophages and HEK293 cells. This study provides a good model to elucidate mechanistic pathway of pharmacological activity of herb medicines in the future. 
Plant-originated glycoprotein has anti-oxidative and anti-inflammatory effects on dextran sulfate sodium-induced colitis in mouse

Present study demonstrated the anti-inflammatory effects of glycolprotein isolated from Gardenia Jasminoides Ellis (GJE) fruits on the colitis induced by dextran sulfate sodium (DSS). The GJE glycoprotein has a scavenging property to inhibit the intracellular ROS production and myeloperoxidase activities in RAW 264.7 cells, $\mathrm{NO}$ production and iNOs, COX-2 and NF- $\kappa \mathrm{B}$, inflammation-related mediators, activity in DSSinduced mice were also reduced. However, the activities of catalase, superoxide dismutase and glutathione peroxidase were increased after a supplement of GJE glycoprotein. Present investigation suggests that GJE glycoprotein is a potential therapeutic agent for ulcerative colitis [28].

\section{Exogenous nitric oxide inhibits IRS-1 expression in rat hepatocytes and skeletal myocytes}

Insulin response is believed to be mediated through tyrosine phosphorylation of the receptor itself and substrates like insulin receptor substrate (IRS)-1 [29]. Nitric oxide (NO) was reported to inhibit insulin binding to its receptors [30]. In this issue, Badal et al. report that exogenous NO inhibits IRS-1 expression in rat hepatocytes and skeletal myocytes [31]. These findings provide further evidence that NO may be a potent molecular modulator of insulinmediated signal transduction and may play a significant role in the pathogenesis of type 2 diabetes mellitus.

\section{Hepatoprotective effect of total flavonoids from Laggera alata against carbon tetrachloride-induced injury in primary cultured neonatal rat hepatocytes and in rats with hepatic damage}

The nine mixture of flavonoids of $L$. alata at the concentration of $50 \mu \mathrm{g} / \mathrm{ml}$ was shown to be able to inhibit the leakage of ALT and AST from primary hepatocytes caused by $\mathrm{CCl}_{4}$. In vivo, oral administration of $50 \mathrm{mg} / \mathrm{kg}$ of the flavonoids significantly reduced the level of AST, ALT and albumin in the serum, and improved liver damage as analyzed by histopathological examination [32, 33]. The protection of hepatic damage caused by $\mathrm{CCl}_{4}$ is due to the ability of flavonoids to scavenge free radicles.

\section{Angiopoietin-1 improvs regional myocardial reperfusion in swines}

Ischemic heart disease is a leading public health concern in the developed world. Despite maximal therapy, a proportion of patients with symptoms of chronic ischemia are refractory to conventional drug treatments or revascularization techniques. Successful therapeutic angiogenesis has been reported with vascular endothelial growth factor (VEGF) and fibroblast growth factor (FGF) in ischemic animal models [34]. However, recent phase II controlled trials using VEGF and FGF2 demonstrated only minimal clinical benefits with no improvement in myocardial perfusion at follow-up [35]. This study investigates the long-term angiogenic effects of ANG-1 and VEGF in a swine chronic myocardial ischemia model. Circumflex coronary artery by ameroid constrictor, animals were injected with recombinant adenoviral vectors carrying either human ANG-1 $(n=9)$, human VEGF165 $(n=10)$ or empty vector $(n=7)$ into the left ventricle free wall supplied by the constricted artery. Results showed that microvascular densities in the left ventricles of animals that received AdANG-1 and AdVEGF were significantly higher than animals that received empty vector 12 weeks after gene transfer. ANG-1, but not VEGF, contributed to enhanced regional perfusion by increasing arteriolar density of large-size $(50-100 \mu \mathrm{m})$ arterioles. These data demonstrate that gene transfer of ANG-1 and VEGF enhances angiogenesis, but ANG-1 promotes sustained improvement of ventricular perfusion that expedites recovery of ischemic myocardium via arteriogenesis [36]. Importance of ANG-1 in embryonic heart development has been well documented. There is increasing evidence suggesting that ANG-1 also plays a critical role in early-phase angiogenesis. ANG-1 is the first growth factor identified to exhibit a potent anti-permeability effect on blood vessels. This occurs even in the presence of strong permeability-inducing factors, such as VEGF and other inflammatory molecules. 


\section{NBC contains cassette II in the heart}

The proton concentration in the cardiovascular system is important for maintaining cardiac function [37]. Cardiac cells have precise regulatory mechanisms to extrude acids from the cytoplasm. More than $40 \%$ of acid extrusion in cardiac myocytes occur by $\mathrm{Na} / \mathrm{HCO}_{3}$ transport [38]. The carrier protein is proposed as an $\mathrm{Na} / \mathrm{HCO}_{3}$ cotransporter with the 1:1 stoichiometry of $\mathrm{Na}^{+}$ versus $\mathrm{HCO}_{3}^{-}$. This study examined the tissuespecific expression of two electroneutral $\mathrm{Na} / \mathrm{HCO}_{3}$ cotransporter $(\mathrm{NBCn} 1)$ variants that differ from each other by the presence of the N-terminal 123 amino acids (cassette II). Northern blot and PCR that can distinguish the deletion variant from the non-deletion variant in rat and human tissues. Result demonstrated that the $\mathrm{NBCnl}$ variant containing cassette II is almost absent in tissues including brain, kidney; and pancreas, where NBCnl has been extensively examined [39].

\section{References}

1. Aizaki H., Choi K.S., Liu M., Li Y.J. and Lai M.M.C., Polypyrimidine-tract-binding protein is a component of the HCV replication complex and necessary for RNA synthesis. J. Biomed. Sci. (this issue).

2. Ito T., Tahara S.M. and Lai M.M.C., The 3'-untranslated region of hepatitis $\mathrm{C}$ virus RNA enhances translation from an internal ribosomal entry site. J. Virol. 72: 8789-8796, 1998.

3. Ling M., Kanayama M., Roden R. and Wu T.C., Preventive and therapeutic vaccines for HPV-associated cervical cancers. J. Biomed. Sci. 7: 341-356, 2000.

4. Peng S., Trimble C., Ji H., He L., Tsai Y.C., Macaes B., Hung C.F. and Wu T.C., Characterization of HPV-16 E6 DNA vaccines employing intracellular targeting and intercellular spreading strategies. J. Biomed. Sci. 12: 689-700, 2005.

5. Lin C.T., Tsai Y.C., He L., Calizo R., Chou H.H., Chang T.C., Soong Y.K., Hung C.F. and Lai C.H., A DNA vaccine encoding a codon-optimized Human Papillomavirus Type 16 E6 gene enhances CTL response and antitumor activity. J. Biomed. Sci. (this issue).

6. Miretti M.M., Walsh E.C., Ke X., Delgado M., Griffiths M., Hunt S., Morrison J., Whittaker P., Lander E.S., Cardon L.R., Bentley D.R., Rioux J.D., Beck S. and Deloukas P., A high-resolution linkage disequilibrium map of the human major histocompatibility complex and first generation of tag single-nucleotide polymorphisms. Am. J. Hum. Genet. 76: 634-646, 2005.

7. De La Vega F.M., Isaac H., Collins A., Scafe C.R., Halldorsson B.V., Su X., Lippert R.A., Wang Y., LaigWebster M., Koehler R.T., Ziegle J.S., Wogan L.T., Stevens J.F., Leinen K.M., Olson S.J., Guegler K.J., You X., Xu L.H., Hemken H.G., Kalush F., Itakura M., Zheng
Y., de The G., O'Brien S.J., Clark A.G., Istrail S., Hunkapiller M.W., Spier E.G. and Gilbert D.A., The linkage disequilibrium maps of three human chromosomes across four populations reflect their demographic history and a common underlying recombination pattern. Genome Res. 15: 454-462, 2005.

8. Helgason A., Yngvadottir B., Hrafnkelsson B., Gulcher J. and Stefansson K., An Icelandic example of the impact of population structure on association studies. Nat. Genet. 37: 90-95, 2005.

9. Yang H.C., Lin C.H., Hsu C.L., Hung S.I., Wu J.Y., Pan W.H., Chen Y.T. and Fann C.S., A comparison of major histocompatibility complex SNPs in Han Chinese residing in Taiwan and Caucasians. J. Biomed. Sci. (this issue).

10. Huang Y.C., Guh J.H. and Teng C.M., Denbinobinmediated anticancer effect in human K562 leukemia cells: role in tubulin polymerization and Bcr-Abl activity. J. Biomed. Sci. 12(1): 113-121.

11. Baker B.E. and Kestler D.P., Effects of siRNAs in combination with gleevec on K-562 cell proliferation and Bcr-Abl expression. J. Biomed. Sci. (this issue).

12. Burmester T. and Hankeln T., Neuroglobin: a respiratory protein of the nervous system. News Physiol. Sci. 19: 110113, 2004.

13. Lutz P.L. and Milton S.L., Negotiating brain anoxia survival in the turtle. J. Exp. Biol. 207: 3141-3147, 2004.

14. Milton S.L., Nayak G., Lutz P.L. and Prentice H.M., Gene transcription of neuroglobin is upregulated by hypoxia and anoxia in the brain of the anoxia-tolerant turtle. J. Biomed. Sci. (this issue).

15. Karczmar A.G., Acute and long lasting central actions of organophosphorus agents. Fundam. Appl. Toxicol. 4: S1S17, 1984.

16. Zhu H., Zhou W., Li X.R., Ma T., Ho I.K. and Rockhold R.W., Methyl parathion increases neuronal activities in the rat locus coeruleus. J. Biomed. Sci. 11: 728-732, 2004.

17. Hoskins B. and Ho I.K., Tolerance to organophosphorus cholinesterase insecticides, In: Chambers J.E. and Levis P.E. (Eds.), Organophosphates: Chemistry, Fate, and Effects. Academic Press, San Diego, 1992, pp. 285-297.

18. Metcalf D.R. and Holmes J.H., EEG, psychological and neurological alterations in humans with organophosphorus exposure. Ann. N.Y. Acad. Sci. 160: 357-365, 1969.

19. Sun T.T., Paul I.A. and Ho I.K., Motor functions but not learning and memory are impaired upon repeated exposure to sub-lethal doses of methyl parathion. J. Biomed. Sci. (this issue).

20. Kullak-Ublick G.A., Hagenbuch B., Stieger B., Schteingart C.D., Hofmann A.F., Wolkoff A.W. and Meier P.J., Molecular and functional characterization of an organic anio transporting polypeptide cloned from human liver. Gastroenterology 109: 1274-1282, 1995.

21. Abe T., Kakyo M., Tokui T., Nakagomi R., Nishio T., Nakai D., Nomura H., Unno M., Suzuki M., Naitoh T., Matsuno S. and Yawo H., Identification of a novel gene family encoding human liver-specific organic anion transporter LST-1. J. Biol. Chem. 274: 17159-17163, 1999.

22. Chen C.J., Chuang Y.C., Lin T.M. and Wu H.Y., Malignant neoplasms among residents of a blackfoot disease-endemic area in Taiwan: high-arsenic artesian well water and cancers. Cancer Res. 45: 5895-5899, 1985.

23. Lu W.J., Tamai I., Nezu J.N., Lai M.L. and Huang J.D., Organic anion transporting polypeptide-C and arsenic uptake. J. Biomed. Sci. (this issue). 
24. Li L., Jiao L. and Lau B.H., Protective effect of gypenosides against oxidative stress in phagocytes, vascular endothelial cells and liver microsomes. Cancer Biother. 8: 263-272, 1993.

25. Tanner M.A., Bu X., Steimle J.A. and Myers P.R., The direct release of nitric oxide by gypenosides derived from the herb Gynostemma pentaphyllum. Nitric. Oxide 3: 359$365,1999$.

26. Huang T.H., Razmovski-Naumovski V., Salam N.K., Duke R.K., Tran V.H., Duke C.C. and Roufogalis B.D., A novel LXR- $\alpha$ activator identified from the natural product Gynostemma pentaphyllum. Biochem. Pharmacol. 70: 1298-1308, 2005.

27. Huang T.H., Li Y., Razmovski-Naumovski V., Tran V.H., Li G.Q., Duke C.C. and Roufogalis B.D., Gypenoside XLIX isolated from Gynostemma pentaphyllum inhibits nuclear actor- $\kappa \mathrm{B}$ activation via a PPAR- $\alpha$-dependent pathway. J. Biomed. Sci. (this issue).

28. Oh P.S. and Lim K.T., Plant originated glycoprotein has anti-oxidative and anti-inflammatory effects on dextran sulfate sodium-induced colitis in mouse. J. Biomed. Sci. (this issue).

29. DeFronzo R.A., Bonadonna R.C. and Ferrannini E., Pathogenesis of NIDDM: a balanced overview. Diabetes. Care 15: 318-368, 1992.

30. McGrowder D., Ragoobirsingh D. and Dasgupta T., Decreased insulin binding to mononuclear leucocytes and erythrocytes from dogs after $S$-nitroso- $N$-acetylpenicillamine administration. BMC Biochem. DOI:10.1186/14712091-3-1.

31. Badal S., Brown P.D. and Ragoobirsingh D., Exogenous nitric oxide inhibits IRS-1 expression in rat hepatocytes and skeletal myocyt. J. Biomed. Sci. (this issue).

32. Kuo P.L. and Lin C.C., Green tea constituent (-)-epigallocatechin-3-gallate inhibits Hep G2 cell proliferation and induces apoptosis through p53-dependent and Fas-mediated pathways. J. Biomed. Sci. 10: 219-227, 2003.
33. Wu Y., Wang F., Zheng Q., Lu L., Yao H., Zhou C., $\mathrm{Wu} \mathrm{X}$. and Zhao Y., Hepatoprotective effect of total flavonoids from Laggera alata against carbon tetrachloride-induced injury in primary cultured neonatal rat hepatocytes and in rats with hepatic damage. J. Biomed. Sci. (this issue).

34. Crottogini A., Meckert P.C., Vera Janavel G., Lascano E., Negroni J., Del Valle H., Dulbecco E., Werba P., Cuniberti L., Martinez V., De Lorenzi A., Telayna J., Mele A., Fernandez J.L., Marangunich L., Criscuolo M., Capogrossi M.C. and Laguens R., Arteriogenesis induced by intramyocardial vascular endothelial growth factor 165 gene transfer in chronically ischemic pigs. Hum. Gene Ther. 14: 1307-1318, 2003.

35. Henry T.D., Annex B.H., McKendall G.R., Azrin M.A., Lopez J.J., Giordano F.J., Shah P.K., Willerson J.T., Benza R.L., Berman D.S., Gibson C.M., Bajamonde A., Rundle A.C., Fine J. and McCluskey E.R., The VIVA trial: vascular endothelial growth factor in ischemia for vascular angiogenesis. Circulation 107: 1359-1365, 2003.

36. Shim W., Li W., Zhang L., Ong H.C., Li S., Song I.C., Bapna A., Ge R., Lim Y.T., Chuah S.C., Sim E. and Wong P., Angiopoietin-1 improvs regional myocardial reperfusion in swines. J Biomed Sci (this issue).

37. Orchard C.H. and Kentish J.C., Effects of changes of $\mathrm{pH}$ on the contractile function of cardiac muscle. Am. J. Physiol. 258: C967-C981, 1990.

38. Lagadic-Gossmann D., Buckler K.J. and Vaughan-Jones R.D., Role of bicarbonate in $\mathrm{pH}$ recovery from intracellular acidosis in the guinea-pig ventricular myocyte. J. Physiol. 458: 361-384, 1992.

39. Lee H.J., Yang H.S., Kippen J., Yun C.C. and Choi I., NBC contains cassette II in the heart. J. Biomed. Sci. (this issue). 